\title{
Potential of Polycyclic Aromatic Hydrocarbon-Degrading Bacterial Isolates to Contribute to Soil Fertility
}

\author{
Maryam Bello-Akinosho, ${ }^{1,2}$ Rosina Makofane, ${ }^{2,3}$ Rasheed Adeleke, ${ }^{2,4}$ Mapitsi Thantsha, ${ }^{1}$ \\ Michael Pillay, ${ }^{3}$ and George Johannes Chirima ${ }^{2,5}$ \\ ${ }^{1}$ Department of Microbiology and Plant Pathology, University of Pretoria, Lynnwood Road, Hatfield, Pretoria 0002, South Africa \\ ${ }^{2}$ Agricultural Research Council-Institute for Soil, Climate and Water (ARC-ISCW), 600 Belvedere Street, Arcadia, \\ Pretoria 0001, South Africa \\ ${ }^{3}$ Department of Biotechnology, Vaal University of Technology, Vanderbijlpark 1900, South Africa \\ ${ }^{4}$ Unit for Environmental Science and Management, North-West University, Potchefstroom Campus, Potchefstroom 2520, South Africa \\ ${ }^{5}$ Centre for African Ecology, School of Animal, Plant and Environmental Sciences, University of the Witwatersrand, \\ Wits 2050, South Africa
}

Correspondence should be addressed to Rasheed Adeleke; adeleker@arc.agric.za

Received 29 April 2016; Revised 11 August 2016; Accepted 4 September 2016

Academic Editor: Dilfuza Egamberdieva

Copyright (C) 2016 Maryam Bello-Akinosho et al. This is an open access article distributed under the Creative Commons Attribution License, which permits unrestricted use, distribution, and reproduction in any medium, provided the original work is properly cited.

\begin{abstract}
Restoration of polycyclic aromatic hydrocarbon- (PAH-) polluted sites is presently a major challenge in agroforestry. Consequently, microorganisms with PAH-degradation ability and soil fertility improvement attributes are sought after in order to achieve sustainable remediation of polluted sites. This study isolated PAH-degrading bacteria from enriched cultures of spent automobile engine-oil polluted soil. Isolates' partial $16 \mathrm{~S}$ rRNA genes were sequenced and taxonomically classified. Isolates were further screened for their soil fertility attributes such as phosphate solubilization, atmospheric nitrogen fixation, and indoleacetic acid (IAA) production. A total of 44 isolates were obtained and belong to the genera Acinetobacter, Arthrobacter, Bacillus, Flavobacterium, Microbacterium, Ochrobactrum, Pseudomonas, Pseudoxanthomonas, Rhodococcus, and Stenotrophomonas. Data analysed by principal component analysis showed the Bacillus and Ochrobactrum isolates displayed outstanding IAA production. Generalized linear modelling statistical approaches were applied to evaluate the contribution of the four most represented genera (Pseudomonas, Acinetobacter, Arthrobacter, and Rhodococcus) to soil fertility. The Pseudomonas isolates were the most promising in all three soil fertility enhancement traits evaluated and all isolates showed potential for one or more of the attributes evaluated. These findings demonstrate a clear potential of the isolates to participate in restorative bioremediation of polluted soil, which will enhance sustainable agricultural production and environmental protection.
\end{abstract}

\section{Introduction}

Certain soil nutrients are vital for the growth and survival of plants in either small or large quantities. Those essential nutrients needed in large quantities are called macronutrients and include nitrogen, phosphorus, and potassium [1] but are, however, present in soil in limiting amounts [2] which therefore necessitate the addition of inorganic fertilizers such as NPK $[1,3]$. A large portion of the inorganic phosphorus in NPK is, however, rapidly immobilized and becomes unavailable for uptake by plants [4]. To overcome this, some soil bacteria are known to possess abilities for converting immobilized forms of phosphorus to readily available forms. They also fix atmospheric nitrogen to ammonia and subsequently nitrates and produce and modulate indoleacetic acid (indole-3-acetic acid, IAA) in the form of auxin [5]. They are usually associated with plant root or soil and are referred to as Plant Growth Promoting Rhizobacteria (PGPR) [6-8]. Bacteria with these abilities are indispensable in improving soil fertility $[9,10]$. Thus, PGPR are envisaged to be a suitable alternative to chemical fertilizers $[7,9,11]$.

Agricultural land may be exposed to pollution by polycyclic aromatic hydrocarbons (PAHs) via mining or when 
there is spillage of petroleum products. Polycyclic aromatic hydrocarbons are a ubiquitous and recalcitrant group of organic environmental pollutants [12], known for their hydrophobic nature, which greatly reduces their availability for degradation and promotes their persistence in soil. In spite of this, a number of bacterial genera have been reported to possess specific mechanisms for degradation of PAHs [1316]. This process is termed microbial bioremediation [17], which is an economic and ecofriendly way of soil remediation where bacteria degrade the hydrocarbons in soil to nontoxic or less toxic end products $[17,18]$. The degradation ability is an adaptation mechanism and once adapted, the degrading microorganisms have accelerated metabolism, which necessitates nutrient stimulation, which can be overcome by microorganisms with innate characteristics of nutrient addition to the soil. This ensures sustainability of the longterm process of bioremediation.

The ultimate aim of any bioremediation process is to restore polluted land to a prepollution state. Given the fact that contaminated soils are often nutrient poor [19], bacteria, which are able to simultaneously degrade PAHs and enhance soil fertility, are valuable as bioaugmentation strains in phytoremediation [18]. Such combination of attributes is indispensable for sustainable agricultural production and environmental protection particularly in the mining and agroforestry sectors. Very few studies have been reported in this respect $[18,20]$. The present study aimed to evaluate, in vitro, the potential roles of $\mathrm{PAH}$-degrading isolates to solubilize phosphates, fix atmospheric nitrogen, and produce IAA as an exploration of their ability to contribute to soil fertility and restorative bioremediation.

\section{Materials and Methods}

2.1. Soil Preparation. Agricultural soil with no history of pollution was collected from a research farm of the Agricultural Research Council, Vegetable and Ornamental Plant Institute, Pretoria, South Africa $\left(25^{\circ} 36^{\prime} 04.2^{\prime \prime} \mathrm{S} ; 28^{\circ} 22^{\prime} 01.3^{\prime \prime} \mathrm{E}\right)$. The soil is of alluvial origin and classified as an Oakleaf soil form [21]. Sampling was done from the topsoil $(0-250 \mathrm{~mm})$. The soil was ground and sieved through a $2 \mathrm{~mm}$ sieve to remove solid particles and minimize heterogeneity. Parameters including particle size distribution, $\mathrm{pH}$, cation exchange capacity (CEC), and nutrient levels were analysed before contamination with spent engine oil. These are shown in Table 1.

Contamination with spent automobile engine oil, whose PAH content was previously determined, was performed by mixing $0 \mathrm{~g}$ (control), $5 \mathrm{~g}$, and $50 \mathrm{~g}$ of oil per kilogram of soil. The contaminated soil was biostimulated with vermicompost obtained from the vermicompost laboratory of the Agricultural Research Council, in Pretoria. Biostimulation of soil with vermicompost was done at $0 \%$ (control), $20 \%$, and $40 \%$, thus maintaining and boosting the indigenous soil microbes. Contamination was done prior to biostimulation to reflect the actual occurrence of events on contaminated sites. The experimental design was a factorial experiment.

2.2. Isolation of PAH-Degrading Bacteria. The methods of Hilyard et al. [22] were slightly modified for the isolation of PAH-degrading bacteria from soil samples, which were collected after 10 weeks of treatment. Pure cultures from various treatments of the artificial pollution were isolated after selective enrichment in Bushnell Haas (BH) broth [23] supplemented with three PAHs, naphthalene, phenanthrene, and fluoranthene, that served as the sole source of carbon. Briefly, $1 \mathrm{~g}$ of each soil treatment was aseptically transferred into $250 \mathrm{~mL}$ Erlenmeyer flasks containing $100 \mathrm{~mL} \mathrm{BH} \mathrm{min-}$ imal medium supplemented with $25 \mathrm{mg}$ of phenanthrene or fluoranthene or $50 \mathrm{mg}$ of naphthalene. Two successive enrichments were done with $1 \%(\mathrm{v} / \mathrm{v})$ culture fluid of the preceding enrichment as inoculum for the succeeding subculture at 3-week intervals. The cultures were incubated at $28^{\circ} \mathrm{C}$ with shaking at $175 \mathrm{rpm}$. Aliquots from the second and third enrichments were plated on $\mathrm{BH}$ agar plates and sprayed with the same PAH used in the enrichment. Colonies arising therefrom were subcultured in $\mathrm{BH}$ agar plates and sprayed with the same PAH. The PAH-degrading strains were selected based on the enhanced growth on plates with added $\mathrm{PAH}$ compared to the control plates without added $\mathrm{PAH}$ and they were stored in $50 \%$ glycerol at $-80^{\circ} \mathrm{C}$ for future use.

2.3. Molecular Identification, Phylogenetic, and Community Analyses of Isolates. For bacterial identification, the $16 \mathrm{~S}$ rRNA gene of pure isolates was amplified using primer sets 968R (5'-AAC GCG AAG AAC CTT AC- $\left.3^{\prime}\right)$ and 1401F $\left(5^{\prime}\right.$ CGG TGT GTA CAA GAC CC-3') [24] using a colony PCR approach. All PCR were performed in a thermal cycler $\mathrm{T} 100^{\mathrm{TM}}$ (Bio-Rad, USA) and each $20 \mu \mathrm{L}$ PCR reaction contained $0.2 \mu \mathrm{M}$ of each forward and reverse primers, $10 \mu \mathrm{L}$ of Thermo Scientific 2x Phusion flash High-Fidelity PCR Master Mix, colony template, and sterile nuclease-free water. The PCR conditions were $20 \mathrm{~s}$ of initial denaturation at $98^{\circ} \mathrm{C}, 30$ cycles of $98^{\circ} \mathrm{C}$ for $20 \mathrm{~s}, 56^{\circ} \mathrm{C}$ for $30 \mathrm{~s}, 72^{\circ} \mathrm{C}$ for $30 \mathrm{~s}$, and a final extension at $72^{\circ} \mathrm{C}$ for 5 mins.

Electrophoresis of $5 \mu \mathrm{L}$ amplicons and loading dye was done on an ethidium bromide stained 1\% agarose gel and subsequently visualized with UV radiation in a Bio-Rad Gel Doc EZ Imager (Gel Doc, Bio-Rad, USA). Amplicon clean-up was done using $15 \mu \mathrm{L}$ amplicons on the Nucleospin Gel and PCR Clean-up kit (Macherey-Nagel, Germany). The success of the clean-up process was verified by quantification with Qubit 2.0 ds DNA BR assay kit (Invitrogen, Eugene, USA) and on $1 \%$ agarose gel as described earlier. Sequencing reaction of each purified amplicon contained $60 \mathrm{ng}$ amplicon, $2 \mu \mathrm{L}$ big dye $3.1,0.5 \mu \mathrm{M}$ of forward or reverse primer, $1 \mu \mathrm{L}$ of $5 \mathrm{x}$ sequencing buffer, and sterile nuclease-free water to a final volume of $10 \mu \mathrm{L}$. Sequencing was done bidirectionally using both forward and reverse primers in separate reactions. The sequencing conditions were denaturation at $96^{\circ} \mathrm{C}$ for $1 \mathrm{~min}$, rapid ramp at $96^{\circ} \mathrm{C}$ for $10 \mathrm{~s}$, rapid ramp at $56^{\circ} \mathrm{C}$ for $5 \mathrm{~s}$ for primer annealing, rapid ramp at $60^{\circ} \mathrm{C}$ for $4 \mathrm{mins}$ and finally, and rapid ramp at $4^{\circ} \mathrm{C}$ for holding until purification. Sequencing PCR products were purified using sodium acetate ( $3 \mathrm{M}, \mathrm{pH} 4.6$ ) and ethanol. The purified samples were kept frozen until they were sequenced. Partial 16S rRNA gene sequences were obtained using BigDye cycle sequencing on the ABI3500xl sequencer (Applied Biosystems, USA) 
TABLE 1: Some physical and chemical characteristics of the soil.

\begin{tabular}{|c|c|c|c|c|c|c|c|c|c|c|c|}
\hline \multirow{2}{*}{$\mathrm{pH}\left(\mathrm{H}_{2} \mathrm{O}\right)$} & \multirow{2}{*}{$\mathrm{EC}(\mathrm{mS} / \mathrm{m})$} & \multirow{2}{*}{$\mathrm{Fe}(\mathrm{mg} / \mathrm{kg})$} & \multirow{2}{*}{$\mathrm{Cu}(\mathrm{mg} / \mathrm{kg})$} & \multirow{2}{*}{$\mathrm{Zn}(\mathrm{mg} / \mathrm{kg})$} & \multirow{2}{*}{ Total C (\%) } & \multirow{2}{*}{ Total N (\%) } & \multirow{2}{*}{$\begin{array}{l}\text { P Bray } 1 \\
(\mathrm{mg} / \mathrm{kg})\end{array}$} & \multirow{2}{*}{$\begin{array}{c}\text { CEC } \\
(\mathrm{cmol} / \mathrm{kg})\end{array}$} & \multicolumn{3}{|c|}{ Particle size (\%) } \\
\hline & & & & & & & & & Sand & Silt & Clay \\
\hline .60 & 0.52 & 49.72 & 2.09 & 3.63 & 0.232 & 0.31 & 28.93 & 13.917 & 76.0 & 8.0 & 16.0 \\
\hline
\end{tabular}

of the Forestry and Agricultural Biotechnology Institute (FABI), University of Pretoria, South Africa. Sequences obtained were manually inspected using BioEdit (version 7.2.5, http://www.mbio.ncsu.edu/BioEdit/bioedit.html).

Preliminary identification of the isolates was done by aligning each sequence against sequences on the National Centre for Biotechnology Information (NCBI) GenBank using the basic alignment search tool, BLAST [25]. The mothur software pipeline [26] was used to cluster sequences into operational taxonomic units (OTUs) at sequence similarity of $97 \%$ or more. For taxonomic assignments, OTU representatives were aligned against sequences on the NCBI GenBank using BLAST. For phylogeny reconstruction, OTU representative sequences along with closely related sequences in the GenBank were selected for multiple sequence alignments using Mafft [27]. Multiple sequence alignments were edited and used to construct a neighbor-joining tree by using a maximum composite likelihood model and 1000-bootstrap replications in the MEGA6 [28].

\section{Assessment of Soil Fertility Attributes}

3.1. Phosphate Solubilization Assay. The ability of the isolated $\mathrm{PAH}$-degrading bacteria to solubilize insoluble inorganic phosphate was investigated in the National Botanical Research Institute's Phosphate (NBRIP) growth medium [29]. The medium contains insoluble tricalcium phosphate $\left(\mathrm{Ca}_{3}\left(\mathrm{PO}_{4}\right)_{2}\right)$, as source of phosphate. Ten microliters of a 48-hour nutrient broth culture was dispensed into wells created on the medium and incubated at $30^{\circ} \mathrm{C}$. Positive result for solubilization of phosphate was characterized by a clear halo around the inoculum well after 5-7 days of incubation. Phosphate solubilization index (PSI) describes the ability of the isolates to solubilize insoluble phosphate on culture plates; it is a ratio of the total diameter of the well and halozone to the diameter of the well [30].

Phosphate solubilization index (PSI)

$$
=\frac{(\text { well }+ \text { diameter of halozone })}{(\text { diameter of well })} \text {. }
$$

3.2. Nitrogen-Fixation Assay. The Burks's nitrogen-free culture medium was used to screen isolates for atmospheric nitrogen-fixing ability. The appearance of appreciable growth within 7 days of aerobic incubation at $28^{\circ} \mathrm{C}$ was indicative of the isolates' nitrogen-fixing ability.

3.3. Indoleacetic Acid (IAA) Assay. The isolates were inoculated on a $1 \%$ tryptophan culture broth and incubated at $28^{\circ} \mathrm{C}$ for 48 hours with continuous agitation at $130 \mathrm{rpm}$. The culture broths were subsequently centrifuged at $10,000 \mathrm{rpm}$ for $10 \mathrm{~min}$ at $4^{\circ} \mathrm{C}$. Exactly $1 \mathrm{~mL}$ of the supernatant was mixed with $2 \mathrm{~mL}$ of Salkowsky's reagent (SR). The mixture was shaken and kept at prevailing ambient temperature in the dark for $30 \mathrm{~min}$. The development of a pink coloration indicated the production of IAA. Subsequent quantification of IAA was done on a spectrophotometer at a wavelength of $540 \mathrm{~nm}$ [31]. A mixture of IAA and SR typically results in the formation of tris-(indole-3-acetato) iron (iii) complex which is displayed as the pink coloration. Therefore, IAA production was measured in the complex by a spectrophotometer and the obtained reading was used to calculate the IAA content by extrapolation from a standard curve of pure IAA.

\subsection{Statistical Analyses}

3.4.1. Principal Component Analysis Comparison of Isolated Bacteria. A principal component analysis (PCA) was used to assess the ability of the isolates to perform soil fertility functions, which included solubilization of phosphate and production of indoleacetic acid, and the extent to which the isolates were different in their abilities to perform these. The principal component analysis was run in XLSTAT, Version 2015 (Addinsoft to Microsoft Excel 2013, New York, USA). The data was coded such that two principal ordination axes, which represented phosphate solubilization and indole acetic production, were extracted and biplots were plotted where arrow represented each function in the direction of its maximum change. Species were shown as points representing the capability of each one along that particular functional arrow. Long arrows indicate high capability for that function. Species occupying positions close to or beyond the tip of an arrow were deemed strongly positively correlated with and influenced by that function. Those at the opposite end were less strongly affected. The PCA model illustrates which species occur together and which ones are further apart in functional capability.

3.4.2. Statistical Model Fitting. The bacteria were grouped with respect to the genus they belong to as Pseudomonas, Rhodococcus, Arthrobacter, and Acinetobacter. All other less prevalent bacteria isolates were placed in one category, others. A contribution to soil fertility was defined as a genus' ability to (i) produce indoleacetic acid, (ii) fix atmospheric nitrogen, or (iii) solubilize phosphorous. Generalized linear modelling techniques in SPSS version 21.0 were applied to assess whether each genus contributed significantly to enhancing soil fertility. For each genus, the first step was assessing whether the ability to produce indoleacetic acid, solubilize phosphorus, or fix atmospheric nitrogen was significantly different from just a neutral effect $[32,33]$. Our models were compared against null models using the Likelihood Ratio 
TABLE 2: OTUs in relation to the phyla and the number of sequences they contain. The OTUs were computed using mothur software pipeline [26].

\begin{tabular}{|c|c|c|c|c|}
\hline OTUs & $\begin{array}{l}\text { Number of } \\
\text { sequences }\end{array}$ & Accession numbers of sequences & Genus & Phylum \\
\hline OTU 1 & 1 & KR185703_10_5A4 & Ochrobactrum & Proteobacteria \\
\hline OTU 2 & 1 & KR185716_10_5A8 & Rhodococcus & Actinobacteria \\
\hline OTU 3 & 2 & KR185719_10_6A1, KR185718_10_3A2 & Acinetobacter & Proteobacteria \\
\hline OTU 4 & 1 & KU216390_10_7A4 & Pseudoxanthomonas & Proteobacteria \\
\hline OTU 5 & 1 & KM578849_10_1E & Rhodococcus & Actinobacteria \\
\hline OTU 6 & 2 & KM578846_10_1C, KR185712_10_8A5 & Pseudomonas & Proteobacteria \\
\hline OTU 7 & 1 & KU216391_10_9A4 & Flavobacterium & Bacteriodetes \\
\hline OTU 8 & 2 & KR185715_10_1B2, KR185714_10_1B1 & Rhodococcus & Actinobacteria \\
\hline OTU 9 & 2 & KR185731_10_1B3, KR185732_10_7A3 & Microbacterium & Actinobacteria \\
\hline OTU 10 & 2 & KR185730_10_11A, KR185729_10_9A3 & Bacillus & Firmicutes \\
\hline OTU 11 & 17 & $\begin{array}{c}\text { KR185710_10_8A4, KR185713_10_11C, KR185697_10_3A3, } \\
\text { KR185709_10_8A3, KR185696_10_3A1, KR185701_10_4A4, } \\
\text { KR185693_10_1A8, KR185695_10_2A3, KR185706_10_6A2, } \\
\text { KR185699_10_4A2, KR185704_10_5A5, KM578847_10_1B, } \\
\text { KR185700_10_4A3, KR185707_10_7A6, KR185702_10_5A3, } \\
\text { KR185705_10_5A7, KR185698_10_4A1 }\end{array}$ & Pseudomonas & Proteobacteria \\
\hline OTU 12 & 2 & KU216393_10_11F, KU216392_10_9A6 & Stenotrophomonas & Proteobacteria \\
\hline OTU 13 & 5 & $\begin{array}{c}\text { KM578848_10_1D, KR185727_10_11G, KR185726_10_11E, } \\
\text { KR185725_10_11D, KR185723_10_7A2 }\end{array}$ & Arthrobacter & Actinobacteria \\
\hline OTU 14 & 1 & KU216394_10_11H & Pseudomonas & Proteobacteria \\
\hline OTU 15 & 1 & KR185728_10_11J & Arthrobacter & Actinobacteria \\
\hline OTU 16 & 3 & KR185720_10_9A5, KR185722_10_11M, KR185721_10_11K & Acinetobacter & Proteobacteria \\
\hline
\end{tabular}

Tests to judge if the specific contribution was significant. If significant, model fit (i.e., model adequacy) was assessed using the Wald Chi-square statistic [32, 33]. If model was adequate, assessment of which genus contributed most to the particular soil fertility function was evaluated. For this, ANOVA in conjunction with Tukey HSD Tests were applied.

\section{Results and Discussion}

4.1. Isolation, Identification, and Community Analyses of PAH-Degrading Bacteria. Forty-four PAH-degrading bacteria were isolated from enrichment cultures of simulated pollution soil treatments that were also biostimulated with vermicompost to add nutrients to the soil treatments [34]. Introduction of the pollutant could have slowed down the growth of indigenous soil bacteria but the biostimulation would have allowed the bacteria that could survive the pollution to thrive well. The isolated bacteria were those with PAH metabolism and degradation ability; they demonstrated varying levels of PAH degradation on culture plates, with a good number of them being Gram-negative. However, PAH-degradation potentials (details reported elsewhere) were independent of their Gram reaction. Sequences of the isolates clustered into 16 OTUs (Table 2). Taxonomic assignments revealed that the bacteria belonged to the phyla Proteobacteria, Firmicutes, Actinobacteria, and Bacteroidetes (Figure 1 and Table 2) and included the genera Acinetobacter (2 OTUs), Arthrobacter (2 OTUs), Pseudomonas (3 OTUs), and Rhodococcus (3
OTUs). The genera Bacillus, Stenotrophomonas, Microbacterium, Pseudoxanthomonas, Ochrobactrum, and Flavobacterium were also identified, with each of them occurring as either a single isolate or two isolates and clustering into a single OTU. Each of these genera of isolates have previously been associated with PAH degradation in different environmental matrices $[14,35,36]$. This study reported culturable PAHdegrading bacteria isolates. Both culturable and unculturable bacteria are known to be role players in $\mathrm{PAH}$ degradation [37]; in fact, reports are that only about $1 \%$ of total bacteria in soil are culturable [38]. This is no limitation to this study, as the focus of the study is to utilize the culturable isolates in field degradation experiments. Culturable Pseudomonas is also reported by Niepceron and coworkers [38] to be active degraders of naphthalene and phenanthrene in soil.

4.2. Soil Fertility Potentials Evaluation of Isolates. All of the isolates demonstrated potentials for at least one soil fertility potential, and many of them displayed multiple of such potentials.

4.2.1. Phosphate Solubilization. Thirty-one of the 44 isolates were able to solubilize insoluble calcium phosphate on culture plates. The isolates' solubilizing ability was measured as a mean value of the ratio of each halozone diameter to inoculum well diameter (Figure 2). This provided a good qualitative comparison of solubilization ability amongst the isolates. Phosphate solubilization index ranged from 2.17 (exhibited 


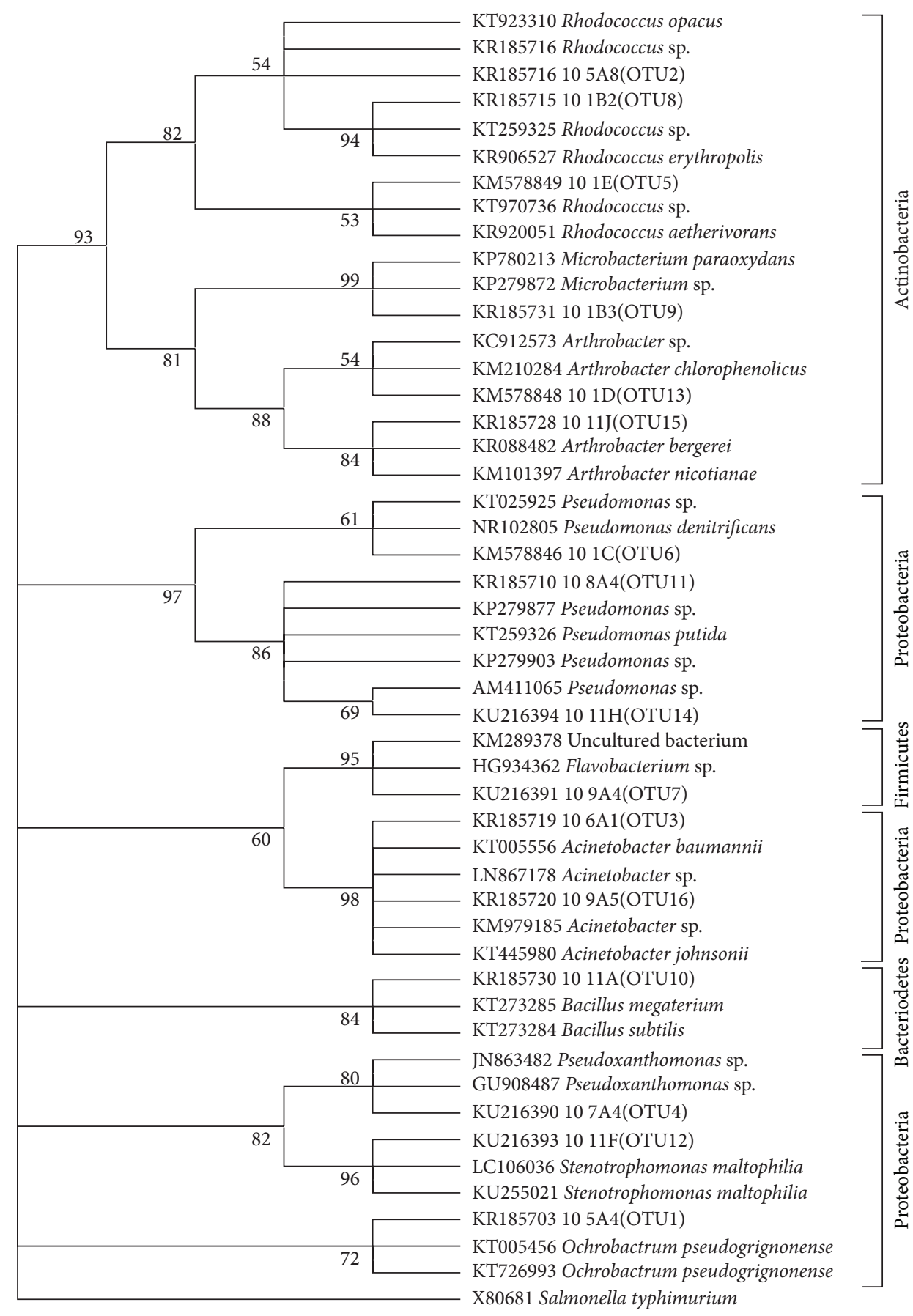

FIGURE 1: Evolutionary relationships of isolated soil bacteria. The evolutionary history was inferred using the neighbor-joining method. The percentage of replicate trees in which the associated taxa clustered together in the bootstrap test (1000 replicates) is shown next to the branches. The evolutionary distances were computed using the Jukes-Cantor method. Salmonella typhimurium was used as the outgroup. Phylogenetic analyses were conducted in MEGA6. One bacterial genus representing each OTU identified is depicted. The sequence analysis was carried out using mothur software in which 16 OTUs were generated at similarities of $97 \%$. The relatives of the representative OTUs were obtained from NCBI. The nucleotides sequences of the representative OTUs showed a range of $98 \%$ to $100 \%$ identity with the homologous sequences reported in GenBank.

by an Acinetobacter sp.) to 7.28 (exhibited by a Pseudomonas sp.). Pseudomonas 1C and Pseudomonas 8A5 exhibited the highest PSI of 7.28 and 5.44, respectively; they both clustered into a single OTU suggesting that they could be very closely related. Phosphate solubilization indices from all the other isolates ranged from 2.17 to 3.44. Some other reports of phosphate solubilization by bacteria isolates are quantitative $[39,40]$ given in $\mathrm{mg} / \mathrm{L}$, when liquid culture media are utilized, 


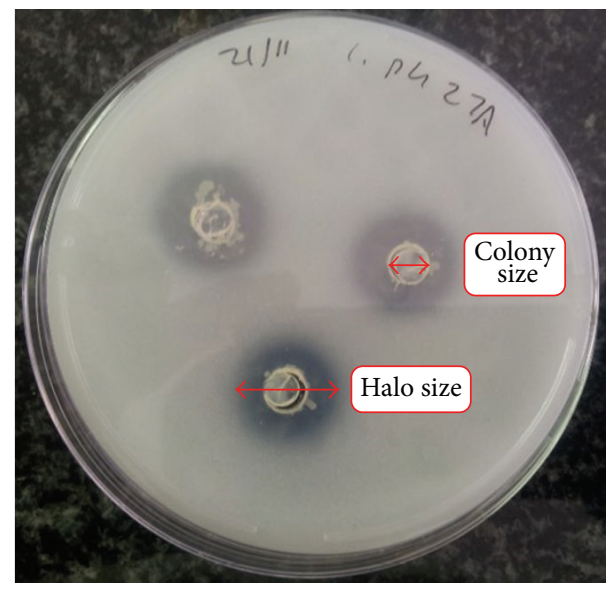

FIGURE 2: Plate showing phosphate solubilization colony size and halo size.

which may or may not be associated with decrease in $\mathrm{pH}$ [40]. This present report of phosphate solubilization is given as indices; this may be quite relevant as an assessment of the relative abilities of the isolates with regard to how far from the source of inoculation the organisms can exert their ability. High phosphate solubilization ability was reported in endophytic Pseudomonas isolates where they stimulated the growth of Pisum sativum [9]. Phosphate solubilization and mineralization by soil bacteria have been deemed an important trait for bacteria to be used as soil inoculants to improve soil fertility and increase phosphate uptake by plants [41], phosphorus being the second major essential macronutrient for plant growth [4]. It is important in several plant metabolic processes such as photosynthesis and macromolecule biosynthesis as well as respiration [42]. Soil bacteria with phosphate solubilization attributes are therefore indispensable in enhancing soil fertility.

4.2.2. Nitrogen-Fixation Ability. The isolates were rated as positive or negative depending on whether they displayed nitrogen fixation or not on culture plates. Thirty-eight isolates displayed growth on the culture plates, thus displaying potential for fixing atmospheric nitrogen, while 6 did not. The ability of the isolates to grow on a nitrogen-free culture medium is suggestive of the fact that the isolates are able to fix nitrogen in the atmosphere to facilitate their growth in a medium devoid of nitrogen, when indeed nitrogen is an essential nutrient for bacteria growth. Attribute of atmospheric nitrogen fixation by soil bacteria would be very important in improving soil fertility and imparting beneficial effects on the promotion of plant growth [43]. Despite the abundance of nitrogen in the atmosphere, plants are unable to use atmospheric nitrogen, unless first converted into utilizable forms such as ammonia and nitrates [44]. Fixation of atmospheric nitrogen, especially biological nitrogen fixation (BNF), would therefore be very essential for nitrogen to be useful to any organism [45]; it is estimated to contribute about half of yearly inputs of nitrogen to the terrestrial ecosystem [46].
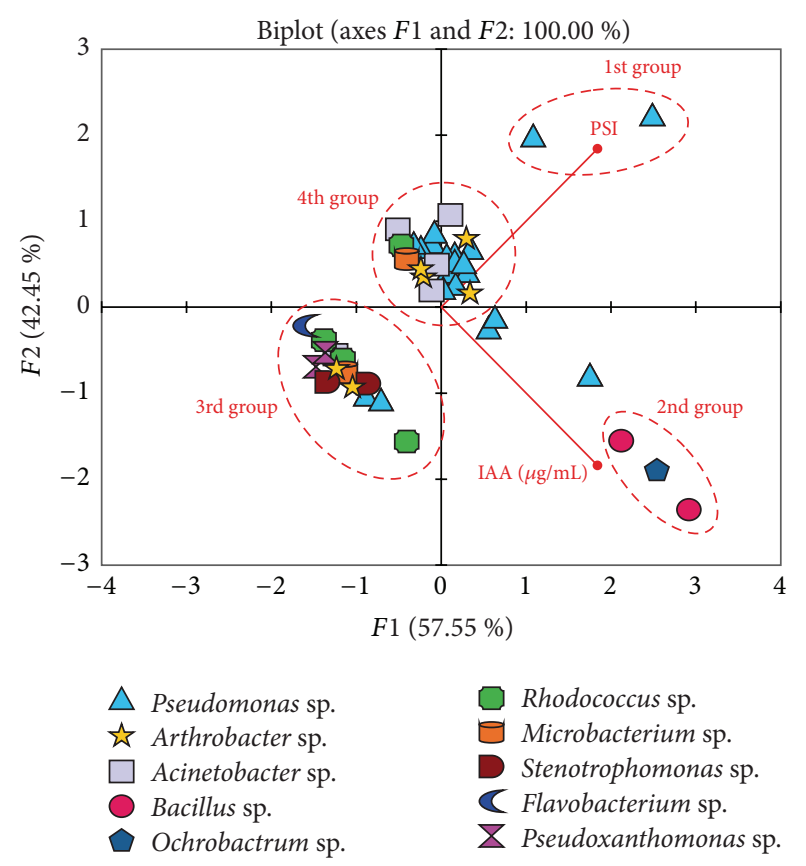

Figure 3: Principal component analysis (PCA) of the 44 isolates in relation to their abilities to solubilize phosphate (PSI) and produce indoleacetic acid (IAA) as a function of their potential ability to contribute to soil fertility.

4.2.3. Indoleacetic Acid Production. The concentration of IAA produced by each isolate was extrapolated from a standard absorbance curve of different concentrations of pure IAA at wavelength of $540 \mathrm{~nm}$. Forty-one of the isolates were able to produce IAA while 3 were not. The concentration of IAA produced ranged from $2.40 \mu \mathrm{g} / \mathrm{mL}$ produced by Acinetobacter $11 \mathrm{M}$ to $38.75 \mu \mathrm{g} / \mathrm{mL}$ produced by Bacillus $11 \mathrm{~A}$. Ochrobactrum 5A4 produced the next highest quantity of IAA at a value of $33.90 \mu \mathrm{g} / \mathrm{mL}$ while the next high quantities were produced by Bacillus 9A3 and Pseudomonas 4A1 at values of $29.40 \mu \mathrm{g} / \mathrm{mL}$ and $22.70 \mu \mathrm{g} / \mathrm{mL}$, respectively.

4.3. Principal Component Analysis (PCA) of Isolates' Capabilities for Solubilization of Phosphate and Production of Indoleacetic Acid. Isolates' ability to enhance soil fertility via phosphate solubilization and IAA production was expressed on PCA (Figure 3). The first principal axis represents PSI and the second, almost of the same magnitude, represents IAA production. The PCA revealed four groups (designated 1st, 2nd, 3rd, and 4th group) of isolates. The 1st group consisted of 2 Pseudomonas isolates that strongly correlated with PSI and 2nd group had 3 isolates strongly correlating with IAA. Inspection of results showed Pseudomonas 1C and Pseudomonas 8A5 exhibited the highest capability to solubilize insoluble tricalcium phosphate on culture plates while Bacillus 11A, Ochrobactrum 5A4, and Bacillus 9A3 were highest in indoleacetic acid production. A diverse group (3rd group) composed of the Flavobacterium, Pseudoxanthomonas, 3 isolates of the Rhodococcus, 2 isolates of the Arthrobacter, all 2 isolates of the Stenotrophomonas, 1 isolate 


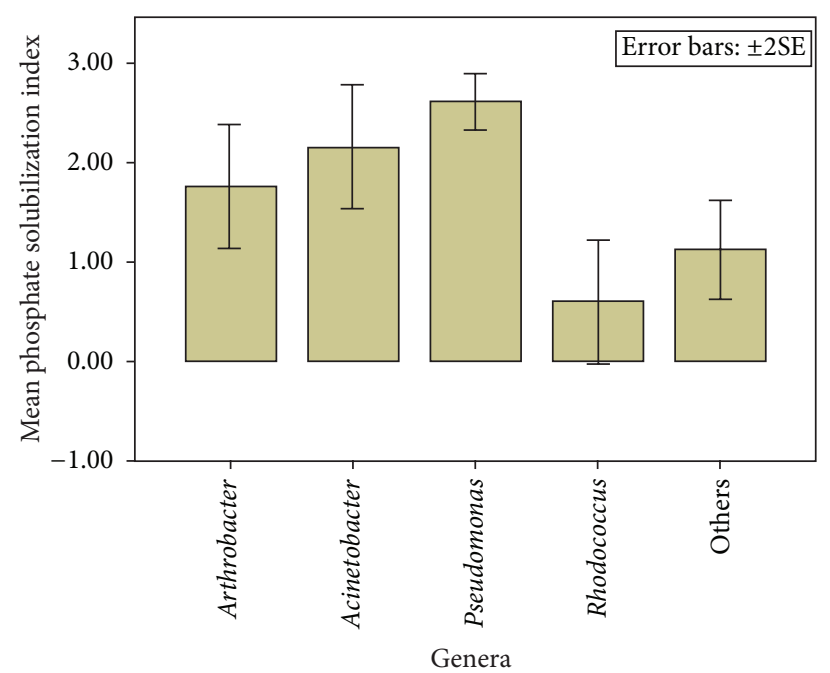

FIGURE 4: Phosphate solubilization indices of the groups of isolates.

of the Acinetobacter, 1 of the Microbacterium, and 2 isolates of the Pseudomonas grouped together, exhibiting weak or negative correlation with PSI. While the 4th group, also with diverse isolates including all 4 Acinetobacter isolates, many of the Pseudomonas, 1 of the Microbacterium, 4 of the Arthrobacter, and 1 of the Rhodococcus, were also weakly correlated with both IAA and PSI.

4.4. Evaluation of Phosphate Solubilization Ability of Isolates by Model Fitting. Contributions of all the genera to solubilization of phosphate were different from 0 and the model was acceptable (Chi-square $=42.818, \mathrm{df}=4$, and $P=0.000$ ). The model exhibited adequate fit for data (Wald Chi-square $=26.186$ and $P=0.00$ ). There were differences in the ability to carry out phosphate solubilization amongst the bacterial genera. Pseudomonads exhibited the highest capability for this trait followed by Acinetobacter while Rhodococus exhibited the least capability $(F=12.66, P=0.000$, and $\mathrm{df}=$ 4) (Figure 4). The ability to solubilize phosphate was not significantly different between Arthrobacter and Acinetobacter. However, the ability to solubilize phosphate was higher for Acinetobacter and Arthrobacter compared to Rhodococus $(P=0.059)$ and $(P=0.008)$, respectively.

4.5. Evaluation of Nitrogen-Fixation Ability of Isolates by Model Fitting. The model with nitrogen fixation was not different from the null model (Chi-square is $1.832 \mathrm{df}=4$, and $P=0.884$ ) and the model fit was not plausible (Wald Chi-square is 1.146 and $P=0.887$ ) implying the odds of fixing nitrogen for all genera were dependent on some other unknown factor, likely duration of incubation.

4.6. Evaluation of Indoleacetic Acid Production of Isolates by Model Fitting. The Likelihood Ratio Chi-Square test was significant (Chi-square is $8.519, \mathrm{df}=4$, and $P=0.008$ ) implying that model was acceptable and that coefficients were different from the null model. The model had adequate fit

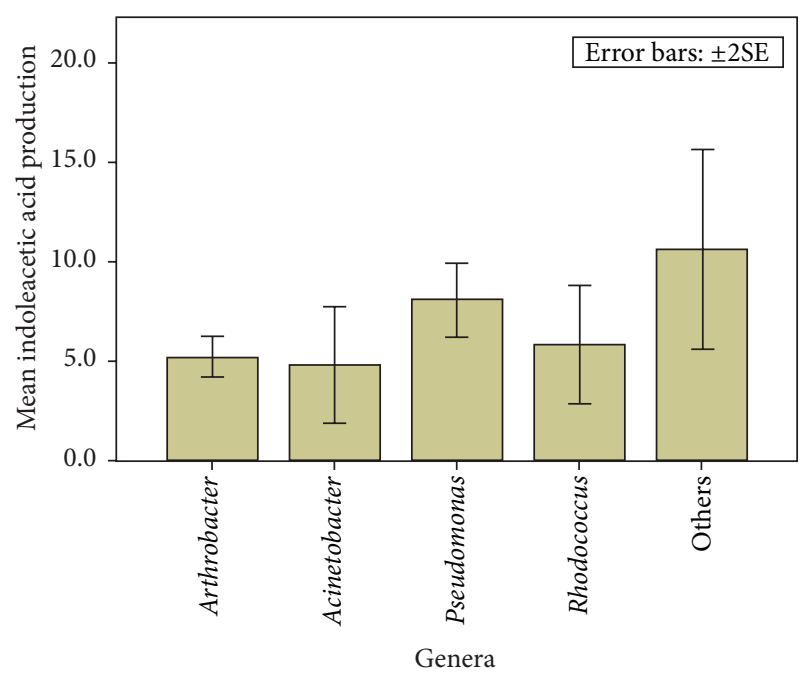

FIGURE 5: Indoleacetic acid production of the groups of isolates.

(Wald Chi-square $=14.690, \mathrm{df}=4$, and $P=0.005$ ). Although Pseudomonads exhibited the highest ability to produce IAA, the differences amongst the genera for this trait were not significant $(F=1.991$ and $P=0.100)$ (Figure 5).

This study identified different genera of bacteria with varying abilities to potentially contribute to soil fertility via phosphate solubilization, atmospheric nitrogen fixation, indoleacetic acid production, or a combination of any two or all three capabilities. Each of the genera exhibited the ability to potentially contribute significantly to soil fertility. Isolates in the genus Pseudomonas demonstrated the greatest ability to potentially contribute to soil fertility. Pseudomonads are known for being highly metabolically versatile in diverse ecosystems, including soil [47]. They have been reported as degrader strains in polluted soils $[14,48]$ as well as possessing several plant growth enhancing abilities $[49,50]$.

The isolates reported here were obtained from simulated PAH-polluted soil. Remediation processes that utilize plants as well as bacteria will find this useful as these isolates play an active role in remediation as well as enhance the growth of the plant involved in phytoremediation. Bacteria are important in the degradation of soil PAHs and are potentially useful in biorestoration of polluted sites [51]. An understanding of the potential capabilities of PAH-degrading bacteria in contributing to the fertility of soil is a pointer towards their usefulness in restoration of remediated land. Bacterial solubilization of phosphorus has been suggested to occur as a consequence of the bacteria releasing some short-chain organic acids [11] whose hydroxyl and carboxyl groups chelate cations bound to phosphate thereby making the phosphate soluble [52]. Short-chain organic acids were also found to inhibit the adsorption of some PAHs onto soil matrices while enhancing their desorption [53]. This shows that some products of metabolism may be responsible for the dual role exhibited by these isolates. It is also important to examine the metabolic genes possessed by the isolates for a better understanding of the isolates' abilities. The genome of one of the Pseudomonas isolates (Pseudomonas sp. 10-1B DDBJ/EMBL/GenBank; 
JYKS00000000) was sequenced, assembled, and annotated [54] and it provided an insight into the probable genes possessed by the isolates. Several phosphatases known to play an active role in phosphates solubilization and mineralization [43] were identified on the genome of the isolate. The gene for enzyme 1-aminocyclopropane-1-carboxylate (ACC) deaminase was also located on the genome. The presence of this enzyme has been reported in some plant growth promoting bacteria (PGPB) $[55,56]$. The ACC deaminase enzyme enables bacteria to utilize ACC as the sole source of nitrogen by metabolizing it to ammonia and $\alpha$-ketobutyrate [57]. Ethylene is known to prevent root elongation in plants and since ACC is the immediate precursor of ethylene metabolism of ACC therefore inhibits ethylene production and root elongation is promoted [56-59]. The possession of these genes by a typical bacterial isolate of this study suggests the suitability of these isolates to perform the dual role of biodegradation and soil fertility enhancement. It was observed from our results that all the degrading isolates could potentially contribute to soil fertility in at least one of the three attributes evaluated. Identification of species level could, perhaps, have explained the differences in their capabilities. These isolates can be further exploited to enhance soil fertility during phytoremediation. Lucy and coworkers [60] as well as $\mathrm{Li}$ and his coworkers [61] demonstrated that PGPB could be very useful as augmenting inoculum in phytoremediation.

\section{Conclusion}

The results of the present study suggest that the reported bacteria isolates have the potential of significant contribution to soil fertility while metabolizing pollutants. Isolates with such dual abilities will prove very useful in instances when sustainable and restorative remediation of polluted soil is desired and when there is need to increase agricultural sustainability in an environmentally friendly way. Such profound capabilities of bacteria exhibited in bioremediation and soil fertility are in high demand in the mining, in agroforestry sectors, and generally in sustainable agricultural production and environmental protection. The isolates in the genus Pseudomonas were most promising solubilizing phosphate; the Bacillus isolates and Ochrobactrum isolate did very well in their indoleacetic acid production. Further study will be undertaken to establish the isolates identity to species level, the metabolic products produced by them, and their genetic composition.

\section{Data Access}

The sequences obtained have been deposited in the GenBank database with accession numbers KM578846-KM578849, KR185693-KR185707, KR185709, KR185710, KR185712KR185716, KR185718-KR185723, and KR185725-KR185732.

\section{Competing Interests}

The authors declare that there is no conflict of interest regarding the publication of this paper.

\section{Acknowledgments}

This work was supported by the NRF Thuthuka (Grant no. TTK1206181390) as well as the Agricultural Research Council, South Africa.

\section{References}

[1] P. J. White and P. H. Brown, "Plant nutrition for sustainable development and global health," Annals of Botany, vol. 105, no. 7, pp. 1073-1080, 2010.

[2] G. A. Divito and V. O. Sadras, "How do phosphorus, potassium and sulphur affect plant growth and biological nitrogen fixation in crop and pasture legumes? A meta-analysis," Field Crops Research, vol. 156, pp. 161-171, 2014.

[3] D. L. Jones, P. Cross, P. J. A. Withers et al., "Review: nutrient stripping: the global disparity between food security and soil nutrient stocks," Journal of Applied Ecology, vol. 50, no. 4, pp. 851-862, 2013.

[4] S. B. Sharma, R. Z. Sayyed, M. H. Trivedi, and T. A. Gobi, "Phosphate solubilizing microbes: sustainable approach for managing phosphorus deficiency in agricultural soils," SpringerPlus, vol. 2, no. 1, article 587, 2013.

[5] G. Gupta, S. S. Parihar, N. K. Ahirwar, S. K. Snehi, and V. Singh, "Plant growth promoting rhizobacteria (PGPR): current and future prospects for development of sustainable agriculture," Journal of Microbial \& Biochemical Technology, vol. 7, pp. 96$102,2015$.

[6] J. W. Kloepper and M. N. Schroth, "Plant growth-promoting rhizobacteria on radishes," in Proceedings of the 4th International Conference on Plant Pathogenic Bacteria, vol. 2, pp. 879882, 1978.

[7] S. H. Ji, M. A. Gururani, and S.-C. Chun, "Isolation and characterization of plant growth promoting endophytic diazotrophic bacteria from Korean rice cultivars," Microbiological Research, vol. 169, no. 1, pp. 83-98, 2014.

[8] O. O. Babalola, "Beneficial bacteria of agricultural importance," Biotechnology Letters, vol. 32, no. 11, pp. 1559-1570, 2010.

[9] N. Oteino, R. D. Lally, S. Kiwanuka et al., "Plant growth promotion induced by phosphate solubilizing endophytic Pseudomonas isolates," Frontiers in Microbiology, vol. 6, article 745, 2015.

[10] M. Ahemad and M. Kibret, "Mechanisms and applications of plant growth promoting rhizobacteria: current perspective," Journal of King Saud University-Science, vol. 26, no. 1, pp. 1-20, 2014.

[11] B. R. Glick, "Plant growth-promoting bacteria: mechanisms and applications," Scientifica, vol. 2012, Article ID 963401, 15 pages, 2012.

[12] Z. Zhang, Z. Hou, C. Yang, C. Ma, F. Tao, and P. Xu, "Degradation of n-alkanes and polycyclic aromatic hydrocarbons in petroleum by a newly isolated Pseudomonas aeruginosa DQ8," Bioresource Technology, vol. 102, no. 5, pp. 4111-4116, 2011.

[13] P. Isaac, L. A. Sánchez, N. Bourguignon, M. E. Cabral, and M. A. Ferrero, "Indigenous PAH-degrading bacteria from oilpolluted sediments in Caleta Cordova, Patagonia Argentina," International Biodeterioration and Biodegradation, vol. 82, pp. 207-214, 2013.

[14] X. Song, Y. Xu, G. Li, Y. Zhang, T. Huang, and Z. Hu, "Isolation, characterization of Rhodococcus sp. P14 capable of degrading high-molecular-weight polycyclic aromatic hydrocarbons and 
aliphatic hydrocarbons," Marine Pollution Bulletin, vol. 62, no. 10, pp. 2122-2128, 2011.

[15] Z. Zhang, L. Gai, Z. Hou et al., "Characterization and biotechnological potential of petroleum-degrading bacteria isolated from oil-contaminated soils," Bioresource Technology, vol. 101, no. 21, pp. 8452-8456, 2010.

[16] S. Dalal, D. P. Panigrahi, G. S. Randhawa, and R. C. Dubey, "Molecular characterisation of high-strength polycyclic aromatic hydrocarbon (PAH)-degrading and phenol-tolerant bacteria obtained from thermal power plant wastewater," Chemistry and Ecology, vol. 28, no. 2, pp. 187-192, 2012.

[17] J.-L. Ramos, S. Marqués, P. van Dillewijn et al., "Laboratory research aimed at closing the gaps in microbial bioremediation," Trends in Biotechnology, vol. 29, no. 12, pp. 641-647, 2011.

[18] V. Ventorino, F. Sannino, A. Piccolo, V. Cafaro, R. Carotenuto, and O. Pepe, "Methylobacterium populi VP2: plant growthpromoting bacterium isolated from a highly polluted environment for polycyclic aromatic hydrocarbon (PAH) biodegradation," The Scientific World Journal, vol. 2014, Article ID 931793, 11 pages, 2014.

[19] E. W. Liebeg and T. J. Cutright, “The investigation of enhanced bioremediation through the addition of macro and micro nutrients in a PAH contaminated soil," International Biodeterioration \& Biodegradation, vol. 44, no. 1, pp. 55-64, 1999.

[20] K. P. Shukla, S. Sharma, N. K. Singh, and V. Singh, "Deciphering rhizosphere soil system for strains having plant growth promoting and bioremediation traits," Agricultural Research, vol. 1, no. 3, pp. 251-257, 2012.

[21] Soil Classification Working Group and C. N. Macvicar, Soil Classification: A Taxonomic System for South Africa, Department of Agricultural Development, 1999.

[22] E. J. Hilyard, J. M. Jones-Meehan, B. J. Spargo, and R. T. Hill, "Enrichment, isolation, and phylogenetic identification of polycyclic aromatic hydrocarbon-degrading bacteria from Elizabeth River sediments," Applied and Environmental Microbiology, vol. 74, no. 4, pp. 1176-1182, 2008.

[23] L. D. Bushnell and H. F. Haas, "The utilization of certain hydrocarbons by microorganisms," Journal of Bacteriology, vol. 41, no. 5, pp. 653-673, 1941.

[24] A. Felske, A. D. L. Akkermans, and W. M. De Vos, "Quantification of $16 \mathrm{~S}$ rRNAs in complex bacterial communities by multiple competitive reverse transcription-PCR in temperature gradient gel electrophoresis fingerprints," Applied and Environmental Microbiology, vol. 64, no. 11, pp. 4581-4587, 1998.

[25] S. F. Altschul, T. L. Madden, A. A. Schäffer et al., "Gapped BLAST and PSI-BLAST: a new generation of protein database search programs," Nucleic Acids Research, vol. 25, no. 17, pp. 3389-3402, 1997.

[26] P. D. Schloss, S. L. Westcott, T. Ryabin et al., "Introducing mothur: open-source, platform-independent, communitysupported software for describing and comparing microbial communities," Applied and Environmental Microbiology, vol. 75, no. 23, pp. 7537-7541, 2009.

[27] K. Katoh and D. M. Standley, "MAFFT multiple sequence alignment software version 7: improvements in performance and usability," Molecular Biology and Evolution, vol. 30, no. 4, pp. 772-780, 2013.

[28] N. Saitou and M. Nei, "The neighbor-joining method: a new method for reconstructing phylogenetic trees," Molecular Biology and Evolution, vol. 4, no. 4, pp. 406-425, 1987.
[29] C. S. Nautiyal, "An efficient microbiological growth medium for screening phosphate solubilizing microorganisms," FEMS Microbiology Letters, vol. 170, no. 1, pp. 265-270, 1999.

[30] M. E. Premono, A. M. Moawad, and P. L. G. Vlek, "Effect of phosphate-solubilizing Pseudomonas putida on the growth of maize and its survival in the rhizosphere," Indonesian Journal of Crop Science, vol. 11, pp. 13-23, 1996.

[31] S. A. Gordon and R. P. Weber, "Colorimetric estimation of indoleacetic acid," Plant Physiology, vol. 26, no. 1, pp. 192-195, 1951.

[32] A. Agresti, An Introduction to Categorical Data Analysis, John Wiley \& Sons, New York, NY, USA, 2nd edition, 1996.

[33] P. McCullagh and J. A. Nelder, Generalized Linear Models, Monographs on Statistics and Applied Probability, Chapman \& Hall, London, UK, 2nd edition, 1989.

[34] Y.-F. Lu and M. Lu, "Remediation of PAH-contaminated soil by the combination of tall fescue, arbuscular mycorrhizal fungus and epigeic earthworms," Journal of Hazardous Materials, vol. 285, pp. 535-541, 2015.

[35] S. C. de la Cueva, C. H. Rodríguez, N. O. S. Cruz, J. A. R. Contreras, and J. L. Miranda, "Changes in bacterial populations during bioremediation of soil contaminated with petroleum hydrocarbons," Water, Air, \& Soil Pollution, vol. 227, no. 3, article 91, 12 pages, 2016.

[36] N. Ali, H. Al-Awadhi, N. Dashti et al., "Bioremediation of atmospheric hydrocarbons via bacteria naturally associated with leaves of higher plants," International Journal of Phytoremediation, vol. 17, no. 12, pp. 1160-1170, 2015.

[37] F. Martin, S. Torelli, D. Le Paslier et al., "Betaproteobacteria dominance and diversity shifts in the bacterial community of a PAH-contaminated soil exposed to phenanthrene," Environmental Pollution, vol. 162, pp. 345-353, 2012.

[38] M. Niepceron, F. Martin-Laurent, M. Crampon et al., "GammaProteobacteria as a potential bioindicator of a multiple contamination by polycyclic aromatic hydrocarbons (PAHs) in agricultural soils," Environmental Pollution, vol. 180, pp. 199-205, 2013.

[39] C. A. Oliveira, V. M. C. Alves, I. E. Marriel et al., "Phosphate solubilizing microorganisms isolated from rhizosphere of maize cultivated in an oxisol of the Brazilian Cerrado Biome," Soil Biology and Biochemistry, vol. 41, no. 9, pp. 1782-1787, 2009.

[40] A. Atekan, Y. Nuraini, E. Handayanto, and S. Syekhfani, “The potential of phosphate solubilizing bacteria isolated from sugarcane wastes for solubilizing phosphate," Journal of Degraded and Mining Lands Management, vol. 1, no. 4, pp. 175-182, 2014.

[41] Y. P. Chen, P. D. Rekha, A. B. Arun, F. T. Shen, W.-A. Lai, and C. C. Young, "Phosphate solubilizing bacteria from subtropical soil and their tricalcium phosphate solubilizing abilities," Applied Soil Ecology, vol. 34, no. 1, pp. 33-41, 2006.

[42] M. S. Khan, A. Zaidi, M. Ahemad, M. Oves, and P. A. Wani, "Plant growth promotion by phosphate solubilizing fungicurrent perspective," Archives of Agronomy and Soil Science, vol. 56, no. 1, pp. 73-98, 2010.

[43] H. Rodríguez, R. Fraga, T. Gonzalez, and Y. Bashan, “Genetics of phosphate solubilization and its potential applications for improving plant growth-promoting bacteria," Plant and Soil, vol. 287, no. 1-2, pp. 15-21, 2006.

[44] J. B. Morgan and E. L. Connolly, "Plant-soil interactions: nutrient uptake," Nature Education Knowledge, vol. 4, no. 8, article 2, 2013. 
[45] C. Santi, D. Bogusz, and C. Franche, "Biological nitrogen fixation in non-legume plants," Annals of Botany, vol. 111, no. 5, pp. 743-767, 2013.

[46] P. M. Vitousek, J. D. Aber, R. W. Howarth et al., "Human alteration of the global nitrogen cycle: sources and consequences," Ecological Applications, vol. 7, no. 3, pp. 737-750, 1997.

[47] A. Peix, M.-H. Ramírez-Bahena, and E. Velázquez, "Historical evolution and current status of the taxonomy of genus Pseudomonas," Infection, Genetics and Evolution, vol. 9, no. 6, pp. 1132-1147, 2009.

[48] G. Coral and S. Karagöz, "Isolation and characterization of phenanthrene-degrading bacteria from a petroleum refinery soil," Annals of Microbiology, vol. 55, no. 4, pp. 255-259, 2005.

[49] F. Ahmad, I. Ahmad, and M. S. Khan, "Screening of free-living rhizospheric bacteria for their multiple plant growth promoting activities," Microbiological Research, vol. 163, no. 2, pp. 173-181, 2008.

[50] A. Esitken, H. E. Yildiz, S. Ercisli, M. F. Donmez, M. Turan, and A. Gunes, "Effects of plant growth promoting bacteria (PGPB) on yield, growth and nutrient contents of organically grown strawberry," Scientia Horticulturae, vol. 124, no. 1, pp. 62-66, 2010.

[51] M. C. Molina, N. González, L. F. Bautista et al., "Isolation and genetic identification of PAH degrading bacteria from a microbial consortium," Biodegradation, vol. 20, no. 6, pp. 789800, 2009.

[52] K. Kpomblekou-A and M. A. Tabatabai, "Effect of organic acids on release of phosphorus from phosphate rocks," Soil Science, vol. 158, no. 6, pp. 442-453, 1994.

[53] C. An, G. Huang, H. Yu, J. Wei, W. Chen, and G. Li, "Effect of short-chain organic acids and $\mathrm{pH}$ on the behaviors of pyrene in soil-water system," Chemosphere, vol. 81, no. 11, pp. 1423-1429, 2010.

[54] M. Bello-Akinosho, R. Adeleke, D. Swanevelder, and M. Thantsha, "Draft genome sequence of Pseudomonas sp. strain $10-1 \mathrm{~B}$, a polycyclic aromatic hydrocarbon degrader in contaminated soil," Genome Announcements, vol. 3, no. 3, Article ID e00325-15, 2015.

[55] S. Shah, J. Li, B. A. Moffatt, and B. R. Glick, "Isolation and characterization of ACC deaminase genes from two different plant growth-promoting rhizobacteria," Canadian Journal of Microbiology, vol. 44, no. 9, pp. 833-843, 1998.

[56] C. Wang, E. Knill, B. R. Glick, and G. Défago, "Effect of transferring 1-aminocyclopropane-1-carboxylic acid (ACC) deaminase genes into Pseudomonas fluorescens strain $\mathrm{CHA} 0$ and its gacA derivative CHA96 on their growth-promoting and diseasesuppressive capacities," Canadian Journal of Microbiology, vol. 46, no. 10, pp. 898-907, 2000.

[57] W. Ma, F. C. Guinel, and B. R. Glick, "Rhizobium leguminosarum biovar viciae 1-aminocyclopropane-1-carboxylate deaminase promotes nodulation of pea plants," Applied and Environmental Microbiology, vol. 69, no. 8, pp. 4396-4402, 2003.

[58] B. R. Glick, C. B. Jacobson, M. M. K. Schwarze, and J. J. Pasternak, "1-Aminocyclopropane-1-carboxylic acid deaminase mutants of the plant growth promoting rhizobacterium Pseudomonas putida GR12-2 do not stimulate canola root elongation," Canadian Journal of Microbiology, vol. 40, no. 11, pp. 911915, 1994.

[59] D. M. Penrose, B. A. Moffatt, and B. R. Glick, "Determination of 1-aminocycopropane-1-carboxylic acid (ACC) to assess the effects of ACC deaminase-containing bacteria on roots of canola seedlings," Canadian Journal of Microbiology, vol. 47, no. 1, pp. 77-80, 2001.

[60] M. Lucy, E. Reed, and B. R. Glick, "Applications of free living plant growth-promoting rhizobacteria," Antonie van Leeuwenhoek, vol. 86, no. 1, pp. 1-25, 2004.

[61] W. Li, L. Xu, J. Wu et al., "Effects of Indole-3-Acetic Acid (IAA), a plant hormone, on the ryegrass yield and the removal of fluoranthene from soil," International Journal of Phytoremediation, vol. 17, no. 5, pp. 422-428, 2015. 

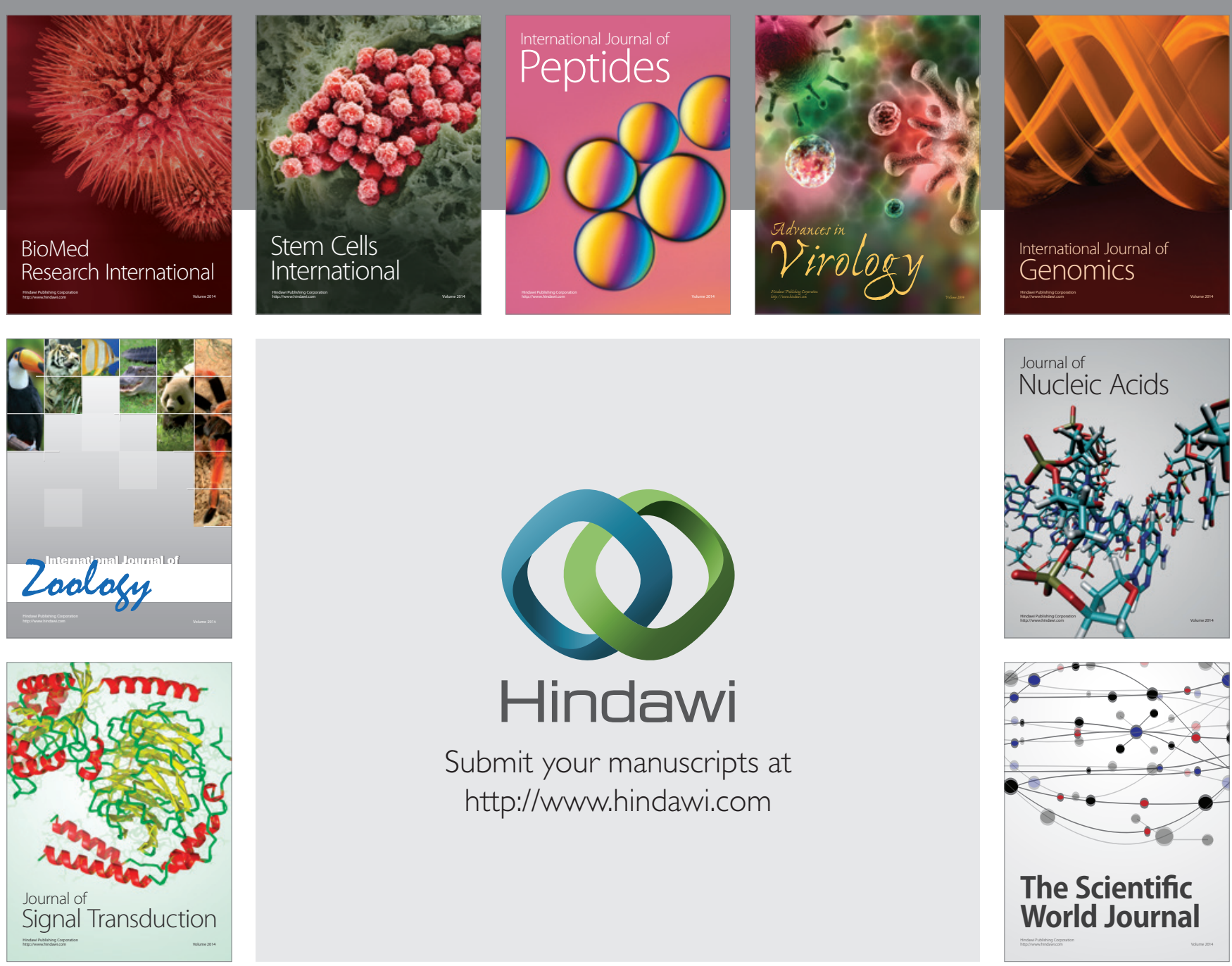

Submit your manuscripts at

http://www.hindawi.com
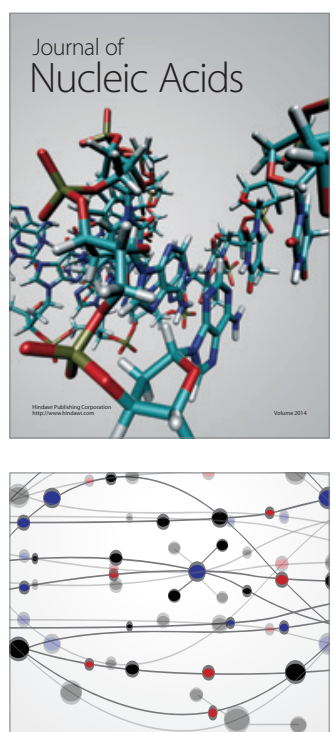

The Scientific World Journal
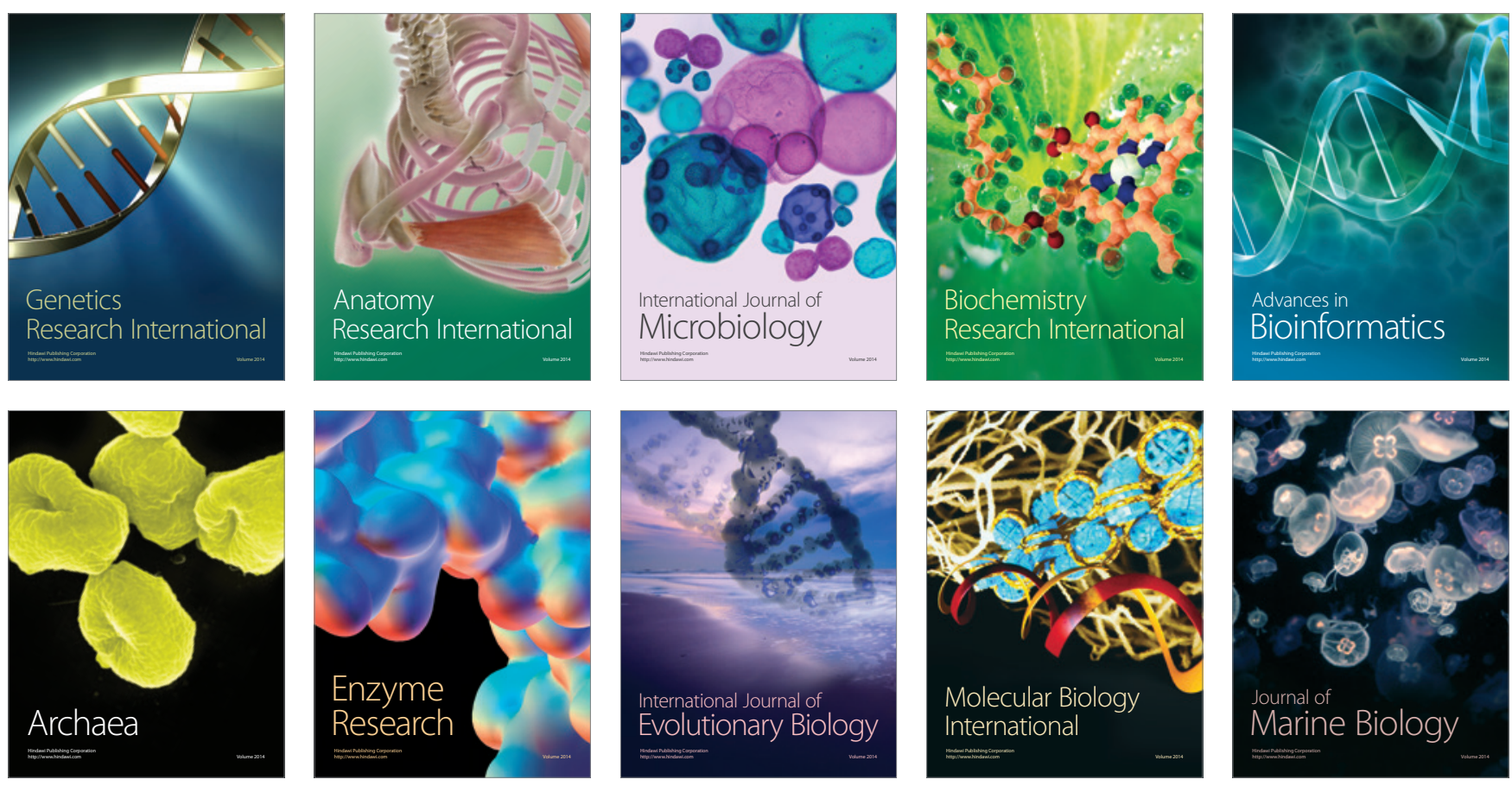